Endocrinology

\title{
The impact of corticosteroids on growth and bone health
}

\section{T Mushtaq, S F Ahmed}

\section{An examination of current evidence}

G lucocorticoids (GC) are important regulators of diverse physiological systems and are often used in the treatment of a number of chronic inflammatory, autoimmune, and neoplastic diseases. It is estimated that $10 \%$ of children may require some form of GC at some point in their childhood. ${ }^{1}$ Impairment of childhood growth with an approximate cortisone dose of 1.5 $\mathrm{mg} / \mathrm{kg} /$ day was first described over 40 years ago; osteopenia in children receiving a prednisolone dose of less than 0.16 $\mathrm{mg} / \mathrm{kg} /$ day has also been reported..$^{23}$ The maintenance of growth and bone health is a complex process that can be influenced not only by drugs, but also by the nutritional status of the patient and the underlying disease process. The purpose of this review is to examine the current evidence for linking GC to adverse growth and bone health in childhood disorders that commonly require GC therapy.

\section{PATHOPHYSIOLOGY}

Loss of bone and deterioration in short term growth are dependent on the type and dose of GC and occur most prominently over the first six months of treatment. ${ }^{4-6}$ Although it is generally believed that GC affect trabecular bone more than cortical bone, a recent study of fractures in children following steroid exposure as part of acute lymphoblastic leukaemia (ALL) treatment showed a high incidence of cortical bone involvement, suggesting that the disease process may interact with GC usage in influencing site of bone loss. ${ }^{78}$

GC have a suppressive effect on osteoblastogenesis in the bone marrow and promote the apoptosis of osteoblasts and osteocytes, thus leading to decreased bone formation. ' Accumulation of apoptotic osteocytes may also explain the so called "osteonecrosis", also known as aseptic or avascular necrosis. There is some evidence to suggest that GC may also increase bone resorption by extending the lifespan of pre-existing osteoclasts. ${ }^{10} \mathrm{GC}$ may also promote calcium loss through the kidneys and gut, and this negative calcium balance can itself lead to increased bone remodelling and osteoclastic activity due to secondary hyperparathyroidism. ${ }^{11}$

High dose GC therapy can attenuate physiological growth hormone (GH) secretion via an increase in somatostatin tone, and the GH response to GH stimulation tests may be reversibly impaired in some cases of steroid exposure. ${ }^{12}{ }^{13} \mathrm{How}$ ever, GC induced growth failure may also be due to direct effects on the growth plate. Infusion of GC into the growth

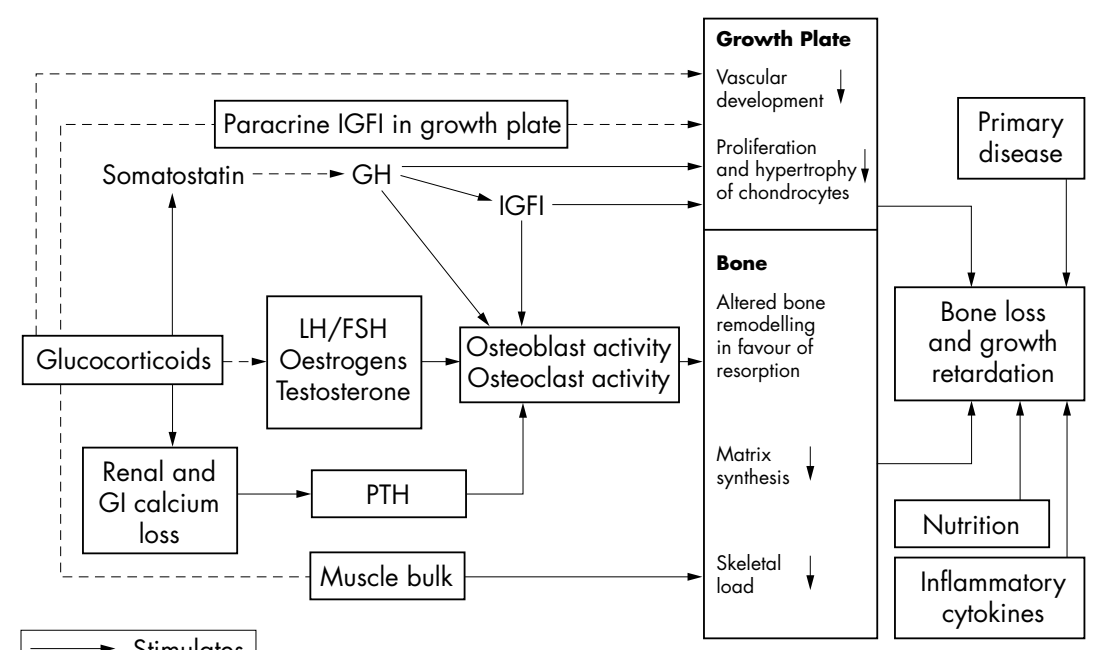

$\begin{aligned} \longrightarrow & \text { Stimulates } \\ --- & \text { Inhibits }\end{aligned}$

Figure 1 Mechanisms of GC induced bone loss and growth retardation. plate leads to a temporary reduction in the growth rate of that leg and may disrupt the growth plate vasculature..$^{14}{ }^{15} \mathrm{GC}$ exposed chondrocytes show reduced proliferation rates and a reversible, prolonged resting period. In vitro studies suggest that local somatotrophic action of GH and IGF-1 may be affected by a number of different mechanisms, including alterations in the activity of the $\mathrm{GH}$ binding protein, down regulation of $\mathrm{GH}$ receptor expression and binding capacity, and a reduction in local IGF-1 production and activity. ${ }^{16-19}$

GC may also impair the attainment of peak bone mass and delay growth through alterations in gonadal function at the level of the pituitary and through direct effects on the gonads. Studies in adults show that GC therapy may be associated with testosterone deficiency as well as reversible gonadotrophin deficiency. ${ }^{20}{ }^{21}$ Levels of other sex steroids such as androstenedione and oestrogen may also be depressed due to adrenal inactivity following chronic GC therapy. ${ }^{22}$ In addition, there is in vitro evidence suggesting that GC impair FSH action, thus reducing oestrogen secretion. ${ }^{23}$

Figure 1 summarises the mechanisms of GC induced bone loss and growth retardation.

\section{ASTHMA, ECZEMA, AND HAY FEVER}

The increasing incidence and prevalence of childhood atopy and the more widespread use of inhaled steroid therapy for asthma prophylaxis probably accounts for the largest group of children who are chronically exposed to steroids. Oral GC therapy in asthma is associated with a delay in growth and puberty, and there is some evidence to suggest that final height may also be compromised. ${ }^{24}$ Systemic exposure to inhaled steroids may be higher with metered dose inhalers and dry powder devices where $80 \%$ of the drug is deposited in the oropharynx. Although earlier studies did not show a relation between inhaled steroids and growth, there is now good evidence in children with relatively mild asthma that inhaled steroids can temporarily slow growth and alter bone and collagen turnover. The magnitude of this effect may be influenced by the dose delivery system as well as the systemic bioavailability of the inhaled steroid used..$^{25}$ This effect may be most pronounced over the first few weeks of treatment. ${ }^{26}$ Long term studies are difficult due to a number of

Abbreviations: ALL, acute lymphoblastic leukaemia; DEXA, dual energy $x$ ray absorptiometry; GC, glucocorticoid; $\mathrm{GH}$, growth hormone; JIA, juvenile idiopathic arthritis 
confounding factors including the plethora of drugs, delivery systems, compliance, and disease severity, but there is no clear evidence that final height is compromised following inhaled GC therapy in children with asthma. Studies of bone mineral density in children with asthma have not shown any significant abnormality but have only concentrated on those children who are on relatively low doses of inhaled steroids. ${ }^{27}$

Some intranasal GC such as budesonide have a very high level of systemic absorption when applied directly to the nasal mucosa; short and intermediate term studies of children on intranasal steroids such as budesonide and beclomethasone also show a deterioration in growth velocity. ${ }^{28}$ Like asthma, there is some suggestion that the effects of these intranasal steroids may be dose dependent and that the newer forms of intranasal steroids such as mometasone furoate may not have these adverse growth effects. $^{29}$ Assessment of short term growth during topical steroid treatment for eczema has also been studied, but the results have been inconclusive. ${ }^{30}$

\section{INFLAMMATORY BOWEL DISEASE}

Longitudinal studies show that the growth velocities of children in the year preceding diagnosis are reduced; growth retardation frequently complicates the clinical course in children. ${ }^{31}$ There is an increased recognition of osteoporosis in adult patients with chronic inflammatory bowel disease. In children with inflammatory bowel disease, retardation of growth and skeletal maturation are widely reported and may be related to disease activity as well as to its treatment. ${ }^{32}$ Vertebral fractures have also been described in children with Crohn's disease with a short or absent history of steroid usage. ${ }^{334} \mathrm{~A}$ cross sectional study of bone mineralisation using dual energy $x$ ray absorptiometry (DEXA) showed evidence of osteopenia even when corrected for sex, height, weight, and puberty. ${ }^{35}$ In this study, the bone status was related to steroid usage but had no relation to disease activity. In a longitudinal study of 55 children, uncorrected total body bone mineral density standard deviation score correlated negatively to cumulative steroid dosage and positively to body mass index. ${ }^{36} \mathrm{~A}$ reduction in bone mineral density of the lumbar spine, femoral neck, and radius may be more prominent in children with Crohn's disease and those children who are of a pubertal or post-pubertal age. The recent introduction of budesonide enemas for treatment of distal colitis has also been reported to be associated with suppression of markers of bone formation. $^{37}$

\section{RENAL DISEASE}

Impaired linear growth is one of the major complications of childhood onset chronic renal insufficiency and its treatment. Final height may be less than the third centile in $50 \%$ of children who enter end stage renal failure in childhood. It is unclear whether such children who are on appropriate vitamin D supplements have a poorer bone mineralisation status. Children with a history of renal insufficiency who receive GC may grow more slowly, have a poorer bone mineralisation status, and may not respond satisfactorily to vitamin $\mathrm{D}$ replacement compared to those who do not receive GC. ${ }^{38}$ The prolonged use of GC is also associated with growth failure and reduced bone mineral density in other childhood chronic renal disease, such as nephrotic syndrome. ${ }^{39}$ Posttransplantation, the cumulative GC dosage may be inversely related to the change in relative height, but this finding is not universal. ${ }^{40}$ Interindividual differences in the handling of GC as assessed by area under the curve estimation rather than dose have shown a stronger association with adverse growth in post-transplantation patients. In nephrotic syndrome, it is not clear whether intermittent GC therapy over a number of years has an adverse effect on growth correlates with final height. ${ }^{41}$ Following transplantation, a given cumulative dose of GC has a lower inhibitory effect on growth velocity, without compromising graft function, when given on alternate days. ${ }^{42}$ Although alternate day GC may not adversely affect final height potential, it may still delay puberty and be associated with a delayed growth spurt. ${ }^{43}$ Substitution of GC with other immunosuppressants improves growth but leads to a higher rate of rejection. The effect of these newer agents on growth and bone health while reducing the need of GC are unclear. Alternative forms of GC, such as deflazacort, an oxazoline derivative of prednisolone, appear to have fewer effects on growth and corticosteroid induced osteoporosis, but are not used in common practice. ${ }^{44}$

\section{ARTHRITIS}

GC are widely used for treating chronic connective tissue diseases in children; as with other inflammatory conditions, there is considerable overlap between the inflammatory process and steroid induced effects on bone health. A failure to develop adequate bone mineralisation is virtually universal in children with juvenile idiopathic arthritis (JIA) and is characterised by a failure of bone formation, with a subsequent failure to undergo the normal increase in bone mass during puberty. ${ }^{45}$ The reduction in bone mineral density and bone mineral gain may be adversely affected if the child was on steroids. ${ }^{46}$ Other studies have not shown any statistical significance of the cumulative dose of corticosteroids on growth, although they did note a reduction in the growth velocity during the first year of treatment which was more apparent in the polyarticular group. ${ }^{47}$ It does appear that good control of disease activity in systemic onset JIA can be achieved by high dose alternate day prednisolone with minimal side effects. ${ }^{48}$ The use of high doses of oral steroids in autoimmune conditions is associated with a prompt decrease of bone formation and collagen synthesis, without any significant changes in bone resorption; however, these negative effects seem to revert after lowering GC dosage. ${ }^{49}$

\section{ACUTE LYMPHOBLASTIC LEUKAEMIA}

GC have been a mainstay of the therapy for childhood ALL. Dexamethasone is now replacing prednisolone as the drug of choice because of its greater lymphocytotoxicity and higher CNS penetration. Recent studies have shown that bone mineralisation status as assessed by bone mineral density, corrected as well as uncorrected for body size, may be adversely affected immediately after completion of treatment. ${ }^{50}$ The fracture incidence during leukaemia treatment has been reported to be as high as $39 \%$; this has been recently confirmed by Strauss et al who have shown a five year cumulative incidence of $28 \%$ for fractures and 7\% for osteonecrosis, with a median follow up of over seven years. ${ }^{8} 5052$ The median time from diagnosis to first fracture was 15 months and most occurred within two years of diagnosis. Older age, pubertal age, the male sex, and dexamethasone have been shown to be independent risk factors for fractures and reduced bone mineralisation. ${ }^{8}$ Previous studies by our group have shown alterations in bone turnover and short term growth of children during leukaemia treatment; these changes were most marked during periods of intensive chemotherapy and high dose systemic glucocorticoid administration. ${ }^{453}$ More recently, we have also reported that the biological potency of dexamethasone in suppressing growth may be 18 times higher than that of prednisolone. ${ }^{6}$

\section{MANAGEMENT}

A number of childhood conditions that require chronic GC therapy may themselves predispose the child to abnormalities of growth and bone health. For instance, poor linear growth and osteoporosis may be presenting features in a child with inflammatory bowel disease. The interaction with other factors such as inflammatory cytokine production, diminished physical activity, alterations in nutritional status, and the use of other 
immunomodulatory agents that may also have bone adverse effects greatly increase the risks posed to the growth and bone health of the child on chronic GC therapy.

The clinical effects on bone health can be divided into those occurring in the short term (fractures and avascular necrosis) and those that may occur over the longer term-that is, increased predisposition for osteoporosis and skeletal deformity. Current studies and clinical observations suggest that children who require long term systemic GC therapy (for more than three months) have a higher incidence of fractures during therapy. For adults, the Royal College of Physicians has issued guidelines on indications for assessing and managing bone health. ${ }^{54}$ In the absence of any clear guidelines for children, it would seem prudent to monitor susceptible children carefully with regular review of bone symptomatology, GC dosage, nutrition (including calcium and vitamin D status), anthropometry (including sitting height), pubertal status, and assessment of bone mineralisation status. Bone mineral status can be assessed by a number of methods and DEXA is by far the most popular method. Unlike adults where a single assessment of bone mineral density by DEXA can predict likelihood of fracture in age related osteoporosis, this relation is not so clear in children with GC induced osteoporosis. Children at risk of GC induced osteoporosis and those displaying growth failure should, therefore have serial bone mineral density assessment to assess a change in status; results need to be carefully interpreted in relation to their sex, age, height, and weight, as well as their disease and its treatment. Current studies of long term follow up of children treated with chemotherapy only regimens for ALL do not show disturbances in final height or bone mineral status, and there are no data to support or refute the claim that prolonged GC therapy in childhood may lead to early osteoporosis in adulthood. ${ }^{55-57}$

Skeletal disproportion has been reported as a possible long term effect of ALL chemotherapy; it is not clear whether this phenomenon of skeletal disproportion is observed in other groups of children requiring chronic GC therapy. ${ }^{58}$ In the absence of any convincing evidence for or against long term osteopenia, it would, again, seem prudent to consider assessing growth and bone mineral status in all patients with a past history of prolonged GC exposure when they reach the end of their second decade and should have acquired peak bone mass. Failure to acquire peak bone mass should prompt longer term monitoring.

Prevention of GC induced growth retardation and adverse bone health could be addressed in a number of cases by judicious use of GC therapy coupled with improved nutrition and promotion of weight bearing activities. In addition, alternate day GC regimens and consideration of GC sparing drugs at an earlier stage than before may be possible preventive measures but need further evaluation. For reasons mentioned earlier, calcium and vitamin D supplementation is generally recommended in patients on GC therapy, although there is little objective clinical evidence to suggest that this practice prevents GC induced osteoporosis in adults or children. As hypogonadism may contribute both to poor growth and impaired bone mineral accretion, addressing hypogonadism in pubertal children on GC therapy should be an important consideration. Recent studies show that recombinant GH treatment may be of benefit in halting the growth retardation and bone loss observed in children on chronic GC therapy. ${ }^{59} 60$

In children, the role of the antiresorptive group of drugs, bisphosphonates has been mostly studied in the field of osteogenesis imperfecta where their use is associated with a reduction in the frequency of fractures, improved bone mass, and mobility. ${ }^{61}$ Bisphosphonate therapy is now used regularly in adults for prevention and treatment of glucocorticoid induced osteoporosis and needs to be carefully evaluated in the paediatric setting. ${ }^{62}$ Acute vertebral fractures can be a debilitating condition that may be associated with a prolonged period of immobility during which the patient may become increasingly susceptible to further fractures. An early resumption of aerobic as well as weight bearing activity, with good analgesic control will require the support of a child oriented physiotherapy and pain relief service.

GC are an effective and necessary form of therapy for a large number of children. In some children, their use may be associated with adverse effects; effective management of GC induced growth retardation and bone health will require improved awareness and better access for monitoring and managing these children, as well as an improved understanding of the contributory factors.

\section{Arch Dis Child 2002;87:93-96}

\section{Authors' affiliations}

T Mushtaq, Dept of Integrative Biology, Roslin Institute, Edinburgh, UK

S F Ahmed, Dept of Child Health, Royal Hospital for Sick Children, Yorkhill, Glasgow, UK

Correspondence to: Dr S F Ahmed, Dept of Child Health, Royal Hospital for Sick Children, Yorkhill, Glasgow G3 8SJ, UK; gcl328@clinmed.gla.ac.uk

\section{REFERENCES}

1 Warner JO. Review of prescribed treatment for children with asthma in 1990. BM 1995:311:663-6.

2 Blodget FM, Burgin L, lezzoni D, et al. Effects of prolonged cortisone therapy on the statural growth, skeletal maturation and metabolic status of children. N Engl J Med 1956:254:636-41.

3 Avioli LV. Glucocorticoid effects on statural growth. BrJ Rheumatol 1993;32 (suppl 2):27-30.

4 Crofton PM, Ahmed SF, Wade JC, et al. Effects of intensive chemotherapy on bone and collagen turnover and the growth hormone axis in children with acute lymphoblastic leukemia. J Clin Endocrinol Metab 1998;83:3121-9.

5 Ahmed SF, Wallace WH, Crofton PM, et al. Short-term changes in lower leg length in children treated for acute lymphoblastic leukaemia. J Pediatr Endocrinol Metab 1999;12:75-80.

6 Ahmed SF, Tucker P, Wallace AM, et al. The effects of prednisolone and dexamethasone on childhood growth and bone turnover during chemotherapy. Clin Endocrinol. In press.

7 Rickers H, Deding A, Christiansen C, et al. Mineral loss in cortical and trabecular bone during high-dose prednisone treatment. Calcif Tis Int 1984:36:269-73.

8 Strauss AJ, Su JT, Dalton VM, et al. Bony morbidity in children treated for acute lymphoblastic leukemia. J Clin Oncol 2001;19:3066-72.

9 Weinstein RS, Jilka RL, Parfitt AM, et al. Inhibition of osteoblastogenesis and promotion of apoptosis of osteoblasts and osteocytes by glucocorticoids. Potential mechanisms of their deleterious effects on bone. J Clin Invest 1998; 102:274-82

10 Hofbauer LC, Gori F, Riggs BL, et al. Stimulation of osteoprotegerin ligand and inhibition of osteoprotegerin production by glucocorticoids in human osteoblastic lineage cells: potential paracrine mechanisms of glucocorticoid-induced osteoporosis. Endocrinology 1999:140:4382-9.

11 Hahn TJ, Halstead LR, Teitelbaum SL, et al. Altered mineral metabolism in glucocorticoid-induced osteopenia. Effect of 25-hydroxyvitamin D administration. J Clin Invest 1979:64:655-65.

12 Pantelakis SN, Sinaniotis CA, Sbirakis S, et al. Night and day growth hormone levels during treatment with corticosteroids and corticotrophin. Arch Dis Child 1972:47:605-8.

13 Hughes NR, Lissett CA, Shalet SM, et al. Growth hormone status following treatment for Cushing's syndrome. Clin Endocrino 1999;51:61-6.

14 Bar-On E, Beckwith JB, Odom LF, et al. Effect of chemotherapy on human growth plate. $J$ Pediatr Orthop 1993;13:220-4.

15 Baron J, Huang Z, Oerter KE, et al. Dexamethasone acts locally to inhibit longitudinal bone growth in rabbits. Am J Physiol 1992;263:E489-92.

16 Jux C, Leiber K, Hugel U, et al. Dexamethasone impairs growth hormone (GH)-stimulated growth by suppression of local insulin-like growth factor (IGF)-I production and expression of $\mathrm{GH}$ - and IGF-I-receptor in cultured rat chondrocytes. Endocrinology 1998;139:3296-305

17 Robson H, Anderson E, Eden OB, et al. Chemotherapeutic agents used in the treatment of childhood malignancies have direct effects on growth plate chondrocyte proliferation. J Endocrinol 1998; 157:225-35

18 Gabrielsson BG, Carmignac DF, Flavell DM, et al. Steroid regulation of growth hormone $(G H)$ receptor and $\mathrm{GH}$-binding protein messenger ribonucleic acids in the rat. Endocrinology 1995;136:209-17.

19 Unterman TG, Phillips LS. Glucocorticoid effects on somatomedins and somatomedin inhibitors. J Clin Endocrinol Metab 1985:61:618-26.

20 Kamischke A, Kemper DE, Castel MA, et al Testosterone levels in men with chronic 
obstructive pulmonary disease with or without glucocorticoid therapy. Eur Respir J $1998 ; 11: 41-5$

21 Sakakura M, Takebe K, Nakagawa S. Inhibition of luteinizing hormone secretion induced by synthetic LRH by long-term treatment with glucocorticoids in human subjects. J Clin Endocrinol Metab 1975;40:774-9.

22 Crilly R, Cawood M, Marshall DH, et al. Hormonal status in normal, osteoporotic and corticosteroid-treated postmenopausal women. J R Soc Med 1978;71:733-6.

23 Hsueh AJ, Erickson GF. Glucocorticoid inhibition of $\mathrm{FSH}$-induced estrogen production in cultured rat granulosa cells. Steroids 1978:32:639-48.

24 Allen DB, Mullen M, Mullen B. A meta-analysis of the effect of oral and inhaled corticosteroids on growth. J Allergy Clin Immunol 1994:93:967-76.

25 Shaw NJ, Fraser NC, Weller PH. Asthma treatment and growth. Arch Dis Child 1997;77:284-6.

26 Doull IJ, Campbell M, Holgate ST. Duration of growth suppressive effects of regular inhaled corticosteroids. Arch Dis Child 1998;78: 172-3

27 Agertoft L, Pedersen S. Bone mineral density in children with asthma receiving long-term treatment with inhaled budesonide. Am J Respir Crit Care Med 1998;157:178-83.

28 Edsbacker S, Andersson KE, Ryrfeldt A. Nasal bioavailability and systemic effects of the glucocorticoid budesonide in man. Eur Clin Pharmacol 1985;29:477-81.

29 Pedersen S. Assessing the effect of intranasa steroids on growth. J Allergy Clin Immunol 2001;108(suppl 1):S40-4.

30 Heuck C, Ternowitz T, Herlin T, et al. Knemometry in children with atopic dermatitis treated with topical glucocorticoids. Pediat Dermatol 1998;15:7-11

31 Markowitz J, Grancher K, Rosa J, et al. Growth failure in pediatric inflammatory bowel disease. J Pediatr Gastroenterol Nutr 1993; 16:373-80.

32 Savage MO, Beattie RM, Camacho-Hubner C, et al. Growth in Crohn's disease. Acta Paediatr Suppl 1999:88:89-92.

33 Cowan FJ, Parker DR, Jenkins HR Osteopenia in Crohn's disease. Arch Dis Child 1995;73:255-6.

34 Semeao EJ, Stallings VA, Peck SN, et al. Vertebral compression fractures in pediatric patients with Crohn's disease. Gastroenterology 1997;112:1710-13.

35 Cowan FJ, Warner JT, Dunstan FD, et al. Inflammatory bowel disease and predisposition to osteopenia. Arch Dis Child 1997:76:325-9.

36 Boot AM, Bouquet J, Krenning EP, et al. Bone mineral density and nutritional status in children with chronic inflammatory bowel disease. Gut 1998;42:188-94

37 Robinson RJ, lqbal SJ, Whitaker RP, et al. Rectal steroids suppress bone formation in patients with colitis. Aliment Pharmacol Ther 1997:11:201-14.

38 Chesney RW, Rose P, Mazess RB, et al. Long term follow-up of bone mineral status in children with renal disease. Pediatr Nephrol 1998;2:22-6.

39 Lettgen B, Jeken C, Reiners C. Influence of steroid medication on bone mineral density in children with nephrotic syndrome. Pediatr Nephrol 1994;8:667-70.

40 Schaefer F, Seidel C, Binding A, et al. Pubertal growth in chronic renal failure. Pediatr Res 1990;28:5-10.

41 Saha MT, Laippala P, Lenko HL. Norma growth of prepubertal nephrotic children during long-term treatment with repeated courses of prednisone. Acta Paediatr 1998;87:545.

42 Jabs K, Sullivan EK, Avner ED, et al. Alternate-day steroid dosing improves growth without adversely affecting graft survival or long-term graft function. A report of the North American Pediatric Renal Transplan Cooperative Study. Transplantation 1996;61:31-6.

43 Polito C, La Manna A, Papale MR, et al. Delayed pubertal growth spurt and norma adult height attainment in boys receiving long-term alternate-day prednisone therapy. Clin Pediatr 1999;38:279-85.

44 Broyer M, Terzi F, Lehnert A, et al. A controlled study of deflazacort in the treatment of idiopathic nephrotic syndrome. Pediatr Nephrol 1997; 11:418-22.

45 Cassidy JT, Hillman LS. Abnormalities in skeletal growth in children with juvenile rheumatoid arthritis. Rheum Dis Clin North Am 1997;23:499-522.

46 Kotaniemi A, Savolainen A, Kroger $\mathrm{H}$, et al Development of bone mineral density at the lumbar spine and femoral neck in juvenile chronic arthritis - a prospective one year followup study. J Rheumato 1998;25:2450-5

47 Saha MT, Verronen P, Laippala $\mathrm{P}$, et al. Growth of prepubertal children with juvenile chronic arthritis. Acta Paediatr 1999;88:724-8.

48 Kimura Y, Fieldston E, Devries-Vandervlugt B, et al. High dose, alternate day corticosteroids for systemic onset juvenile rheumatoid arthritis. $J$ Rheumatol 2000;27:2018-24

49 Conti A, Sartorio A, Ferrero S, et al. Modifications of biochemical markers of bone and collagen turnover during corticosteroid therapy. J Endocrinol Invest 1996;19:127-30.

50 Halton JM, Atkinson SA, Fraher L, et al. Altered mineral metabolism and bone mass in children during treatment for acute lymphoblastic leukemia. J Bone Miner Res 1996;11:1774-83

51 Arikoski P, Komulainen J, Riikonen P, et al. Reduced bone density at completion of chemotherapy for a malignancy. Arch Dis Child 1999;80: 143-8.

52 Halton JM, Atkinson SA, Fraher $L$, et al. Altered mineral metabolism and bone mass in children during treatment for acute lymphoblastic leukemia. J Bone Miner Res 1996:11:1774-83.

53 Crofton PM, Ahmed SF, Wade JC, et al. Effects of a third intensification block of chemotherapy on bone and collagen turnover, insulin-like growth factor I, its binding proteins and short-erm growth in children with acute lymphoblastic leukaemia. Eur J Cancer 1999;35:960-7

54 Eastell R, Reid DM, Compston J, et al. A UK Consensus Group on management of glucocorticoid-induced osteoporosis: an update. J Intern Med 1998;244:271-92.

55 Birkebaek NH, Clausen N. Height and weight pattern up to 20 years after treatment for acute lymphoblastic leukaemia. Arch Dis Child 1998;79:161-4.

56 Kaste SC, Jones-Wallace D, Rose SR, et al. Bone mineral decrements in survivors of childhood acute lymphoblastic leukemia frequency of occurrence and risk factors for their development. Leukemia 2001;15:728-34.

57 Kadan-Lottick N, Marshall JA, Baron AE, et al. Normal bone mineral density after treatment for childhood acute lymphoblastic leukemia diagnosed between 1991 and 1998. J Pediatr 2001;138:898-904.

58 Davies HA, Didcock E, Didi M, et al Disproportionate short stature after cranial irradiation and combination chemotherapy for leukaemia. Arch Dis Child 1994;70:472-5.

59 Rooney M, Davies UM, Reeve J, et al. Bone mineral content and bone mineral metabolism changes after growth hormone treatment in juvenile chronic arthritis. I Rheumato 2000;27: 1073-81.

60 Touati G, Ruiz JC, Porquet D, et al. Effects on bone metabolism of one year recombinant human growth hormone administration to children with juvenile chronic arthritis undergoing chronic steroid therapy. Rheumatol 2000;27: 1287-93.

61 Glorieux FH, Bishop NJ, Plotkin H, et al. Cyclic administration of pamidronate in children with severe osteogenesis imperfecta. N Engl J Med 1998;339:947-52.

62 Adachi JD, Bensen WG, Brown J, et al. Intermittent etidronate therapy to prevent corticosteroid-induced osteoporosis. N Engl J Med 1997;337:382-7. 